\title{
Documentos
}

\section{La mirada del fantasma El velado valor de un archivo gráfico}

Ariel Arnal

\author{
El meu avi s'en va anar a Cuba \\ A bordo del "Català", \\ el millor barco de guerra \\ de la flota d'ultramar \\ El meu avi, habanera, \\ Josep Lluis Ortega i Monasterio, 1968
}

En 1992, poco antes de las Olimpiadas que tuvieron lugar en la ciudad de Barcelona, como parte de la amplia reforma urbanística que remodelaría la cara y espíritu de la Ciudad Condal, desde el Ayuntamiento de Barcelona se llevó a cabo una investigación sobre los Talleres Nuevo Vulcano, edificio histórico que albergaba parte de lo que habían sido los astilleros más importantes del puerto de Barcelona a lo largo de casi 150 años. A modo de certificado de defunción, el edificio debía catalogarse metro a metro, para lo cual se registraron sus muros en el que sería el único soporte que quedaría tras su derribo: la fotografía y el video.

Desahuciado pocos años antes, el edificio presentaba una visión casi postapocalíptica. Parte de sus oficinas parecían abandonadas a toda prisa; se habían dejado en ellas intactos los estantes y gavetas donde se guardaban planos históricos de lo que habían sido emblemáticos vapores, torpederas de la Armada y yates de recreo. Además, mirando al mar se hallaban dos diques flotantes del puerto de Barcelona, de gran valor histórico a punto de ser destazados y vendidos por kilo (o más bien toneladas) de hierro y acero. 


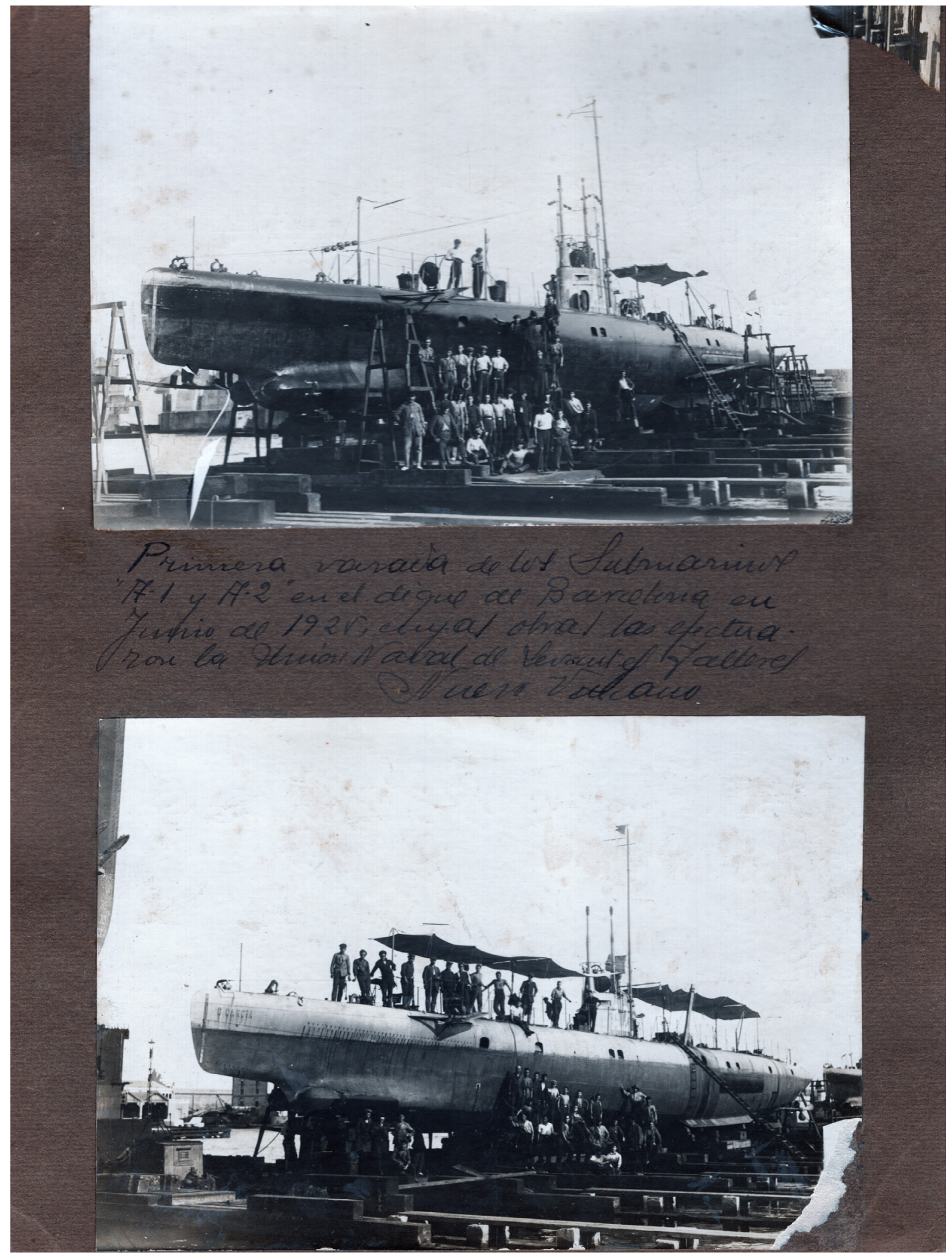

Figura 1. Autor desconocido. Submarinos A1 y A2 en el dique de los Talleres Nuevo Vulcano, Barcelona, octubre de 1925. Colección privada. 
Entre los documentos y planos que atestiguaban la importancia de los Talleres Nuevo Vulcano para la historia industrial de la ciudad se encontraba amontonada una serie de álbumes fotográficos sobre lo que allí se había construido o reparado. Esos álbumes daban cuenta de aburridas fotografías, llenas de detalles técnicos, sin duda de gran valor para ingenieros navales. De igual modo, se encontraban imágenes de barcos, yates y embarcaciones menores posando orgullosas sobre el Mediterráneo, tras su exitosa reparación en el dique seco.

El destino de todo ello era la basura. Sólo algunos planos, los más detallados, levantados pacientemente a mano por ayudantes expertos y tenaces, hallaron cobijo en las bodegas del Museo de Historia de la ciudad de Barcelona. Todo lo demás fue alimento de la industria del papel reciclado para el mundo editorial.

De todo ello, en el suelo sobresalía una carpeta, deshojada y rota por el pasar de los años. En ella se conservaban en cartulina marrón fotografías sepia de embarcaciones fuera de lo común, submarinos de la Armada Española. A tina de tintero y antigua caligrafía, "octubre de 1925" era la fecha que se leía en cada una de las hojas marrones bien conservadas, a pesar de su evidente y dolorosa desarboladura.

Por la descripción escrita casi 70 años antes, se trataba de los submarinos A1 Monturiol y A2 Costa García, los primeros que la historia de la Armada Española afirma fueron fabricados en Italia, entre 1917 y 1919, llamados de clase F Laurentti por los astilleros italianos.

¿Qué nos dice una imagen encontrada milagrosamente entre cosas viejas, llenas de historias guardadas para siempre por la fatalidad del progreso?, ¿qué significa hallarse un archivo privado a punto de desparecer en una planta recicladora?, ¿cómo hacemos hablar a esa fotografía, imágenes balbuceantes en un nostálgico color sepia, tratando de nombrar su historia con apenas vagas sombras del pasado? Rescatar los rastros del pasado y construir con ellos una historia es el trabajo del historiador visual. 
Todo historiador es una mezcla de curioso inquisidor y cotilla del pasado, cuyo placer confeso es vestirse de Sherlock Holmes, Hercule Poirot o moderna Miss Marple. Partir de una historia inicial, un retrato, para enseguida darse a la tarea de buscar pistas y finalmente atar cabos sueltos y reconstruir una narración, es el regocijo y objetivo vital de todo historiador y desde luego también de un historiador visual. Así, esa foto se convierte en verdadero aperitivo de lo que sigue: construir el pasado de manera coherente y comprensible.

Para ello, los historiadores visuales han desarrollo métodos particulares a partir de la metodología del cuestionamiento de fuentes propio de la historia. Ese cuestionamiento se reduce básicamente a contrastar dos o más fuentes de distinto origen, de modo similar a como un periodista de investigación reconstruye el presente... sólo que aquí hablamos de lo acontecido mucho tiempo atrás. El cuestionamiento hermenéutico constituye el primer paso para colocar nuestros datos sobre la mesa. Procede jugar con ellos, como si de piezas de un rompecabezas se tratara. Una vez ordenados, toca darles coherencia, construir frases visuales, episodios desde la mirada del pasado. Hecho eso, la cocina del ayer nos obliga a contar una nueva historia, a narrar lo acontecido y volverlo asible y comprensible para el resto de la gente, curiosos del pasado, amateurs o historiadores profesionales.

Dicho esto, volvamos al puerto de Barcelona, al rastro que de él tenemos en las manos con una fecha, octubre de 1925. ¿Cuáles son esos datos con los que contamos, esas piezas sueltas de nuestro rompecabezas del pasado? A saber, una fotografía en sepia, dos submarinos, dos nombres - A1 Monturiol y A2 Cosme García-, un dique flotante y un álbum deshojado. Eso es lo que nos cuenta la fotografía en cuestión. Toca ahora ser imaginativo y buscar lo que llamamos datos de contexto. El álbum ha sido encontrado en las oficinas de planos y archivos de Talleres Nuevo Vulcano, el que fuera el astillero más importante del puerto de Barcelona desde 1836, para cubrir las necesidades navieras entre la Península, Cuba y Puerto Rico. Frente a nosotros, mirando por la ventana de la sala de planos del astillero, vemos el Mediterráneo, la playa de Sant Sebastià, todo ello como 
apacible marco de dos viejos diques flotantes construidos en 1900. No hay más, sólo eso. Ése es nuestro contexto de partida para emprender la búsqueda de una historia que se esconde a nuestro entendimiento.

A partir de entonces no nos queda más que imaginar hipótesis y comenzar a indagar esas rutas que nos permitirán ir poco a poco cerrando una historia. Hablamos aquí de un archivo privado al borde de la desaparición, de los últimos rastros de lo que había sido pieza fundamental en la segunda industrialización catalana, y que por lo tanto podía responder —como archivo- no sólo a preguntas básicas sobre la historia de la ciudad, sino de la carrera comercial entre Madrid y Barcelona por los mercados europeos. Sabíamos que la información que poseíamos era exigua, pero también percibíamos que estábamos ante un verdadero hilo de Ariadna de un fragmento de la historia marítima española. Esa foto era la luz de alarma de que era preciso convertir kilos de basura en un archivo histórico.

Fue así como arrancó la investigación, el contraste de la información primaria con aquel universo de información relativa al tema - Talleres Nuevo Vulcano y submarino-, aunque fuese de manera tangencial. A partir de los pocos datos antes descritos, esa información exterior fue conformando un orbe con sentido propio. Supimos así que entre los restos de documentos literalmente esparcidos por el suelo de las oficinas de planos de los Talleres Nuevo Vulcano, aparecía el dato vago de que los submarinos de la clase "A" habían sido construidos en Barcelona, en esos astilleros que teníamos enfrente. El dato era impreciso y era necesario comprobarlo.

Por el contrario, encontramos en información de la Armada Española que uno de ellos, el A2 Cosme García, sufrió un grave accidente en el Muelle Viejo de Barcelona el 19 de abril de $1927 .{ }^{1}$ A partir de allí fuimos reconstruyendo y contextualizando la fotografía que poseíamos. Se trataba de los dos primeros de tres submarinos de la clase A, llamada F en Italia, y que habían sido construidos por la Fiat en sus astilleros de La Spezia frente el mar de

1 Revista General de Marina, Madrid, t. 101, 1994, 239. 
Liguria. Entre el mundo de papeles desordenados encontrados en los Talleres Nuevo Vulcano, nada había sobre aquellos dos submarinos. Fue en los archivos de la Armada Española donde aparecieron las fichas técnicas de ambos que, sin duda, alguna vez estuvieron entre las manos de los ingenieros de la Nuevo Vulcano. Así, un archivo público consolidado echaba a la mano lo que por entonces parecía un archivo privado desahuciado.

Supimos así la historia de cada uno de ellos, de sus múltiples visitas de mantenimiento a los diques de la Nuevo Vulcano, de sus azarosos accidentes, del hundimiento y posterior rescate del A2 Costa García en el Muelle Viejo de Barcelona, de su base en el puerto insular en la bahía de Maó, de su baja definitiva en 1931. Eso — simples nombres - nos llevó de la mano a la historia de los submarinos españoles, de aquellos inventores poco comprendidos del siglo xIX, de los fracasos empresariales de Cosme García, el primer proyectista de un submarino, de Narcís Monturiol y su Ictíneo, de Isaac Peral y el primer submarino torpedero. Comprendimos la importancia que para el nacionalismo español significa recurrir a ese patrimonio, que era suyo y que colocaba al submarinismo ibérico en primera línea. Monturiol primero, Cosme García después, consolidaron su fama e importancia en la historia marítima en una vieja fotografía en sepia, rescatada de milagro para la historia. De paso, contribuíamos a un pequeño episodio de la historia y arqueología industrial del puerto de Barcelona, de sus redes comerciales desde el siglo XIX hasta 1992.

¿Qué es un archivo fotográfico? Un depósito de la memoria, suele decirse, de nuestro imaginario iconográfico. Sin embargo, la fotografía, como cualquier imagen que pretenda constituirse en afirmación categórica de nuestro pasado, es tramposa. Es por eso que una fotografía no hace un archivo, porque éste - el archivo - nos brinda la posibilidad, en la medida de lo posible, de contrastar, negar y confirmar lo que vemos frente a nuestros ojos. Sólo un retazo del pasado, un segundo congelado e inmortalizado en las sales de plata de un papel sensible. Eso es una fotografía. Una imagen fotográfica es una palabra, una frase inmersa en un discurso conformado a partir de la suma de otras imágenes. Eso es la narrativa visual. Ésa es la 


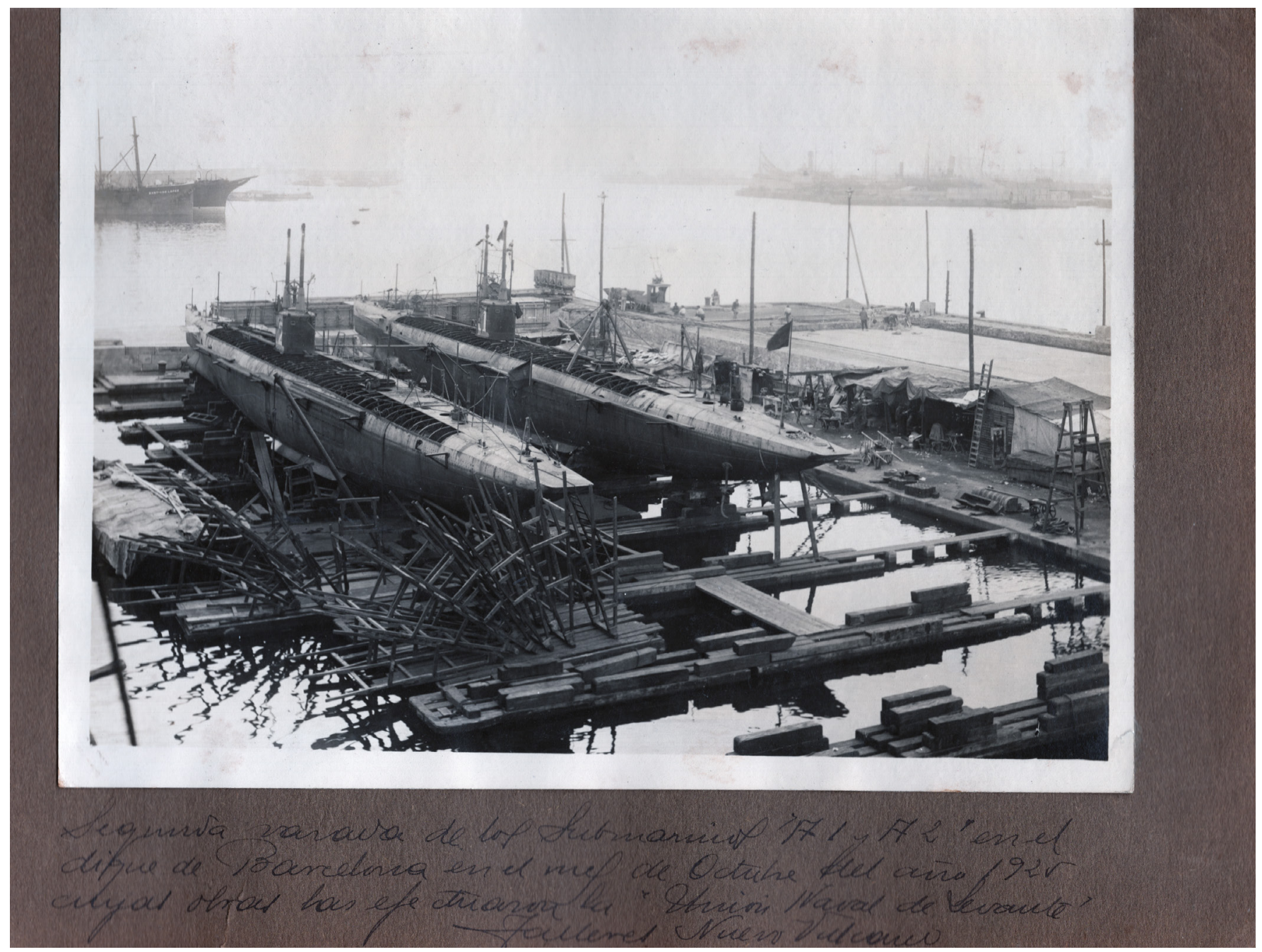

Figura 2. Autor desconocido. Dique flotante en los Talleres Nuevo Vulcano, Barcelona, ca. 1930.

Postal. Colección privada.

razón por la que es preciso buscar datos, rumores que nos permitan atar cabos y contar nuestra propia historia sobre ese pasado de miradas cruzadas entre una fotografía, un fotógrafo, un sujeto y un lector a casi un siglo de distancia.

La memoria no es la verdad del pasado, es el consenso de lo que podemos ser en un futuro próximo. Es por eso que construimos archivos y atesoramos esos objetos de plata y papel sensible, porque constituyen - los constituimos- en el origen de nuestra historia, que es decir de nuestra propia identidad. Es allí, en el archivo, donde levantamos piedra a piedra el atanor de nuestro pasado. Si los archivos clásicos de legajos, palabras y series 
numéricas nos transmiten información mediada, lo archivos gráficos son frases visuales que nos interpelan a la conversación con nuestro propio pasado. Así lo comprendió el Museo de Historia de la ciudad de Barcelona. En 1992 se cerraba un capítulo de la industrialización de la Ciudad Condal, la industria hacía tiempo que había sido trasladada fuera, y los Talleres Nuevo Vulcano resistían necios a la nueva vocación residencial y turística del puerto. Esos documentos, esas fotografías que abrían la conversación tímida y sosegada sobre acontecimientos remotos, pedían a gritos un entierro digno, donde la memoria hablara de ellos para nuestra mejor comprensión del futuro.

Fue así como el objetivo inicial de desguazar las oficinas de Nuevo Vulcano se convirtió en un acto de intervención urgente sobre un archivo gráfico del que hasta entonces se desconocía su existencia. Esa urgencia requirió clasificar, categorizar y jerarquizar la información en tiempo récord inferior a un mes; las compañías constructoras ( $\mathrm{sic}$ ) empezaban a llegar al edificio y esperaban ansiosamente iniciar su derribo. Lo que el escueto tiempo permitía logró salvar información gráfica que a prisa y corre fue clasificada. No hubo tiempo para llevar a cabo una catalogación en forma —eso ya se haría en el propio museo cuando las condiciones lo permitieran-.

En aquellos tiempos de locura olímpica -1992-la información gráfica no era valorada en España como una fuente histórica per se y sólo se utilizaba como ilustración de textos escritos. No existía el concepto hoy afortunadamente arraigado de "historia visual" o "historia gráfica". Aun así, desde el Museo de Historia de la Ciudad se intuía que ahí había algo trascendente, el embrión de alguna cosa que sin duda cobraría importancia con el paso de los años. La tragedia de la inminente desaparición de los Talleres Nuevo Vulcano se convertía paradójicamente en el motivo que llevaba a salvar de inmediato ese archivo gráfico; era como recoger desordenadamente todo lo posible justo antes de un incendio.

Con el transcurrir de los años se han llevado a cabo importantes investigaciones monográficas, tanto del pasado industrial del puerto y astilleros de 
Barcelona como de la navegación peninsular y sus estrechas relaciones con la América hispana. Las viejas fotografías de lo que fue el largo periodo de auge de Talleres Nuevo Vulcano han reaparecido en estos estudios, ora como ilustración, ora como fuente primaria. Los entonces modernos submarinos A1 Monturiol y A2 Cosme García recuperan su lugar en nuestra memoria colectiva, junto a antiguas postales del dique flotante y la fachada de la fábrica. Sin la existencia de archivos gráficos, esa memoria nos habría quedado trunca. La fotografía tiene la magia ilusoria de acercarnos al pasado, "colocarnos allí" en medio de los acontecimientos de tiempos pretéritos, y mirar a los ojos a sus protagonistas. El cajón donde guardamos esa memoria es el archivo, por mucho que lo ordenemos, nos deshagamos de cosas e incluyamos otras nuevas, el cajón de nuestra memoria seguirá siendo eso, ese lugar sagrado por mítico desde el cual edifiquemos argumentalmente nuestro futuro. El archivo gráfico y los fantasmas que pueblan sus imágenes son la mirada del pasado que contempla nuestro presente y cimientan lo que queremos ser hacia el futuro.

\section{Ariel Arnal}

Doctor en estudios humanísticos por la Universidad Rovira i Virgili de Tarragona, maestro y licenciado en historia por la Universidad Iberoamericana y la Universidad de Barcelona respectivamente, es especialista en historia visual, cine y fotografía. Posee una especialidad en patrimonio arquitectónico por el Museo de Historia de la Ciudad de Barcelona. Ha publicado en México y el extranjero obra sobre fotografía de la Revolución Mexicana, los exilios español y chileno en México, cine documental, iconografía y simbología religiosa. Al respecto, sus obras más destacadas incluyen la fotografía de Juan Crisóstomo Méndez, la construcción de la iconografía zapatista, el fotógrafo Walter Reuter y la Guerra Civil Española, la fotografía de Rodrigo Moya, así como el cine documental de Patricio Guzmán. Ha sido profesor invitado en diversas instituciones mexicanas, así como en Chile, Centroamérica, España, Francia y Rusia. 